NACIONAL

\title{
Jara con Barrientos: El caso Víctor Jara ante la justicia universal
}

Jara vs Barrientos: The Victor Jara case before universal justice

\author{
Francisco JARA Bustos \\ Universidad de Chile \\ Francisco Ugás TAPIA \\ Universidad Carlos III de Madrid, España
}

RESUMEN El presente trabajo busca analizar la decisión de 27 de junio de 2016, mediante la cual un jurado de la Corte Distrital del Distrito Medio de Florida, Orlando, Estados Unidos, declaró que Pedro Pablo Barrientos Núñez era culpable de haber participado en la tortura y el asesinato de Víctor Lidio Jara Martínez, crímenes ocurridos en septiembre de 1973. En la primera parte se relata quién fue Víctor Jara y su significación histórica, para luego dar cuenta de las circunstancias de su muerte en el entonces Estadio Chile, emplazado en Santiago de Chile, por oficiales del Ejército. Seguidamente, se analiza el devenir del caso judicial en nuestro país y el problema de que uno de los implicados se encontrara fuera de las fronteras chilenas. Como tercer punto, se examina el proceso en los Estados Unidos de América, y la Torture Victims Protection Act y el Alien Tort Statute como una forma de justicia universal morigerada.

PALABRAS CLAVE Víctor Jara, derechos humanos, justicia universal, Torture Victims Protection Act, Alien Tort Statute, dictadura cívico-militar chilena.

ABSTRACT The present paper seeks to analyze the decision of June 27,2016 , in which a jury of the District Court of the Middle District of Florida, Orlando, United States of America, declared that Pedro Pablo Barrientos Núñez was guilty of having participated in torture and murder of Víctor Lidio Jara Martínez, crimes committed in September of 1973. In the first part it's reported who was Víctor Jara and its historical significance, then given an account of the circumstances of his death in the former Chile Stadium, in Santiago, Chile, by Army officers. Then the future of the judicial case in our country will be analyzed, and the problem of one of those involved outside the Chilean borders. As a 
third point, the process in the United States of America will be examined, as will be the Torture Victims Protection Act and the Alien Tort Statute as a form of universal justice.

KEYWORDS Víctor Jara, human rights, universal justice, Torture Victims Protection Act, Alien Tort Statute, civil-military dictatorship of Chile.

Somos cinco mil aquí en esta pequeña parte de la ciudad. Somos cinco mil. ¿Cuántos somos en total en las ciudades y en todo el país? Somos aquí diez mil manos que siembran y hacen andar las fábricas. ¡Cuánta humanidad con hambre, frío, pánico, dolor, presión moral, terror y locura!

Víctor JARA, SOMOS CINCO MIL

\section{¿Quién es Víctor Jara?}

Víctor Lidio Jara Martínez es un importante referente cultural y político del Chile contemporáneo ${ }^{1}$. Desgraciadamente, su trascendente vida de entrega a su familia y a su Pueblo se vio truncada súbitamente, pocos días después del golpe militar del 11 de septiembre de 1973, por la acción criminal de agentes del Ejército de Chile, quienes lo ejecutaron en el entonces llamado Estadio Chile, rebautizado posteriormente como Estadio Víctor Jara.

Víctor nació el 28 de septiembre de 1932 en la región del Biobío. Hijo de Manuel Jara y de Amanda Martínez, desde pequeño demostró una gran atracción por las artes, especialmente la música y la actuación, por lo que orientó su formación académica y profesional al desarrollo de las mismas. Junto con ello, cultivó una sentida conciencia social y de amor hacia su Pueblo, por lo que asumió la responsabilidad que, como artista, él tenía para con una sociedad que anhelaba ser más justa y democrática. Dichos ideales eran representados, primero, por el partido político en el cual militó, el Partido Comunista, y luego, por el proyecto político que, para él y para muchos compatriotas, representó la Unidad Popular, encabezada por el entonces presidente de la República, Salvador Allende. En sus expresiones artísticas intentó transmitir su mensaje, en el que resaltó la dignidad de la persona humana y bregó por la necesidad de que la justicia social se erigiera como un valor y realidad en nuestro país.

1. Sobre su vida, véase Jara (2007). 
Es recordado mundialmente en canciones de grupos musicales, como Los Fabulosos Cadillacs, Inti-Illimani o U2, en calles, placas, teatros e incluso en el cinturón de asteroides, pues uno de ellos recibió su nombre².

\section{Las circunstancias del golpe y su fallecimiento}

El 11 de septiembre de 1973, las Fuerzas Armadas y de Orden, encabezadas por una Junta de Gobierno, dieron un golpe de Estado que depuso al gobierno democrático dirigido por Salvador Allende. Esta sublevación, que se venía fraguando hace ya tiempo (Herrero, 2014: 300-301; Kornbluch, 2013), puso fin al estado constitucional y democrático vigente y dio inicio a una cruenta dictadura cívico-militar ${ }^{3}$.

En aquella época, Víctor se desempeñaba como profesor e investigador en la Universidad Técnica del Estado (UTE). Esa mañana, el cantautor popular se encontraba en su hogar cuando se enteró del golpe que se estaba desarrollando. Junto a él, estaban Joan Alison Turner Roberts, su cónyuge, y sus dos pequeñas hijas, Manuela y Amanda. Pese a lo que estaba ocurriendo en el país, Víctor estimó necesario trasladarse hasta las dependencias de la universidad, ubicadas en el centro de la capital, no sin antes despedirse de su familia. Ese día estaba previsto que, en la universidad, el presidente de la República inaugurara la exposición «Por la vida. Contra el fascismo», la que nunca se realizó. Luego de que el cantante arribara a la UTE, ésta fue sitiada por efectivos del regimiento Arica del Ejército de Chile, provenientes de la ciudad de La Serena, región de Coquimbo, bajo el mando del entonces capitán Marcelo Moren Brito ${ }^{4}$. Las tropas mantuvieron cercadas las dependencias de la institución universitaria y, al día siguiente, previo disparos de proyectiles de diversa naturaleza hacia el recinto, procedieron a allanar y ocupar sus dependencias, deteniendo masivamente a docentes, alumnos y administrativos. También se asesinó a algunos de los presentes ${ }^{5}$.

Posteriormente, los detenidos, Víctor incluido, fueron trasladados en buses hasta el entonces Estadio Chile, el cual fue habilitado con antelación como recinto de detención, con la coordinación del Comando de Apoyo Administrativo del Ejército, y

2. El 22 de septiembre, a pocos días de su muerte, el astrónomo soviético Nikolai Stepanovich Chernykh nombró al entonces recién descubierto asteroide 2.644 Víctor Jara (Schmadel, 2013: 342).

3. Sobre los alcances del mismo, véase Comisión Nacional de Verdad y Reconciliación (1991).

4. Marcelo Moren Brito fue uno de los represores más brutales del régimen. Participó en la Caravana de la Muerte e integró la Dirección de Inteligencia Nacional (DINA), donde lideró el campo de concentración de Villa Grimaldi. Fue condenado a más de trescientos años de presidio por torturas, ejecuciones, asociación ilícita y desapariciones forzadas que incluían la de su propio sobrino. Fue condenado en 2004 y recluido en el privilegiado penal Cordillera, hasta su cierre, cuando pasó a Punta Peuco. Murió en prisión el 11 de septiembre de 2015.

5. Contamos, entre otros, a Martha Vallejos Buschmann y a Hugo González Araya. Sentencia de la Corte Suprema de Justicia de Chile, rol 22.206-2016, 13 de octubre de 2016. 
resguardado su interior por contingente militar de dotación de diversos regimientos del país, entre ellos, el Regimiento Blindado número 2 de Santiago, el regimiento Esmeralda de Antofagasta, el regimiento Maipo de Valparaíso y el regimiento de Tejas Verdes de San Antonio 6 .

Ese 12 de septiembre, Víctor, encontrándose privado de su libertad, fue ingresado al señalado recinto de detención, para ser luego ubicado con múltiples detenidos en las graderías del lugar7. Reconocido por un oficial, fue derribado de un culatazo y golpeado. Posteriormente, fue separado del resto de las personas detenidas y trasladado a la zona de camarines, ubicada en el subterráneo, habilitada previamente por los militares para la práctica de interrogatorios y torturas a los detenidos. Estos actos se desarrollaron entre los días 13 y 16 de septiembre de 1973, y fueron ejecutados por oficiales del Ejército de Chile. Estas sesiones fueron desarrolladas incluso por personal de la Segunda Fiscalía Militar de Santiago, dependiente del Juzgado Militar respectivo, así como por algunos militares que hasta el día del golpe se encontraban detenidos por el intento de sublevación del 29 de junio de 1973, al mando del sedicioso coronel Souper8.

A partir del 15 de septiembre, las personas que se encontraban detenidas en el Estadio Chile, a excepción de Víctor y otras pocas víctimas, comenzaron a ser trasladadas al Estadio Nacional, locación que también había sido habilitada como recinto de detención. Víctor, junto con Littré Quiroga Carvajal, quien fuera director nacional del Servicio de Prisiones, y Danilo Bartulín Fodich, médico y amigo personal del presidente Allende, fueron separados del grupo que era trasladado al Estadio Nacional por el encargado militar del Estadio Chile, quien ordenó su envío al subterráneo del recinto, específicamente a los camarines, donde se encontraba personal militar. Cuando la mayoría de los detenidos del recinto del Estadio Chile había abandonado tal lugar, oficiales del Ejército de Chile procedieron a ejecutar sumariamente a los prisioneros que no habían sido trasladados. Víctor Jara recibió, al menos, 44 impactos de bala, calibre 9,23 mm, según se establece en el informe de autopsia de la víctima. Las armas que proferían balas de tal calibre sólo eran utilizadas por los oficiales del Ejército de Chile, como los que se encontraban en el recinto'.

6. Lo anterior, según se estableció en la investigación desarrollada por el ministro en visita extraordinaria, Miguel Vázquez Plaza, de lo cual dan cuenta los basamentos respectivos de los procesamientos pronunciados por el referido ministro instructor, de fechas 26 diciembre de 2012 -complementado por resolución de 28 de diciembre del mismo año-, 10 de octubre de 2013, 29 de agosto y 2 de septiembre, ambos de 2014, y en la acusación fiscal dictada el 21 de julio de 2015, todas resoluciones expedidas en la actual causa rol 16.379-2005, a la cual se acumuló la causa rol 108.496-9, en la que originalmente se comenzaron a indagar los hechos criminales perpetrados en la persona de Víctor Lidio Jara Martínez.

7. Sobre la llegada al Estadio Chile, véase Escalante y otros (2013).

8. Sobre el golpe frustrado de 29 de junio de 1973, conocido como Tanquetazo o Tancazo, véase Prats (1985: 620).

9. Según consta en el numeral 7 del fundamento segundo de la acusación de oficio, pronunciada el día 
El cuerpo sin vida de Víctor, junto con el de otras tres personas más, fue hallado por pobladoras que habitaban en las inmediaciones del Cementerio Metropolitano de Santiago, en un terreno baldío, el 16 de septiembre de ese año. Su identificación se debió, en buena medida, a las pobladoras y a la acción de personas como Héctor Herrera Olguín, funcionario del Servicio de Registro Civil e Identificación, en comisión de servicios en el entonces Instituto Médico Legal, quien logró comprobar la identidad del cuerpo y ubicar a su mujer, Joan Turner, para evitar que las autoridades militares intentaran ocultarlo ${ }^{10}$.

\section{El caso judicial en Chile}

El proceso judicial en Chile se inició el 12 de septiembre de 1978, mediante la denuncia que realizó Joan Jara, quien en ese entonces se encontraba radicada en Londres, y fue patrocinada por el abogado Luis Ortiz Quiroga. La referida denuncia fue presentada ante el Quinto Juzgado de Letras en lo Criminal de Santiago, individualizada bajo el rol 108.496-9. La jueza titular de dicho tribunal, Adela Manquilef Vargas, proveyó la querella ordenando la instrucción del respectivo sumario criminal ${ }^{11}$.

Diversas diligencias fueron realizadas, pese a la vigencia del Decreto Ley de Amnistía ${ }^{12}$. Sin embargo, dado el contexto vivido en la época, el proceso criminal no

21 de julio de 2015 por el ministro en visita extraordinaria Miguel Vázquez Plaza, que obra a fojas 11.422 y siguientes de la causa rol 16.379-2005.

10. Esta historia consta en el documental Víctor Jara número 2.547, de Elvira Díaz, que estrenó en Francia el 16 de septiembre de 2013.

11. Este caso fue sustanciado bajo las normas contenidas en el Código de Procedimiento Penal, que establecía un sistema de enjuiciamiento escriturado. Si bien la justicia procedimental criminal chilena ha sido reformada, esta norma continúa siendo aplicable debido a su vigencia en la época de ocurrencia de los hechos, y a lo indicado en la Disposición Transitoria Octava de la Constitución Política de la República, lo cual ha sido ratificado por el Tribunal Constitucional en diversos fallos. Véase, Tribunal Constitucional de la República de Chile, rol 2991-2016-INA. Requerimiento de inaplicabilidad por inconstitucionalidad presentado por Hugo Prado Contreras respecto del artículo 483 del Código Procesal Penal, en los autos rol 39.122, seguidos ante el ministro en visita extraordinaria Mario Carroza de la Corte de Apelaciones de Santiago, en actual conocimiento de la Corte Suprema, por recursos de casación en la forma y en el fondo, bajo el rol 8.642-2015 y rol 1327-09-INA. Requerimiento de inaplicabilidad por inconstitucionalidad de Angélica Carvajal Fuenzalida, respecto de los artículos 274, 424, 109, 110 inciso 1, 499 inciso 3, 61 inciso final del Código de Procedimiento Penal y artículo 483 del Código Procesal Penal, en causa rol 39.224-2003 del Juzgado del Crimen de Viña del Mar.

12. El Decreto Ley 2.191, de 19 de abril de 1978, concedió amnistía por crímenes cometidos entre el 11 de septiembre de 1973 y el 10 de marzo de 1978. Esta autoamnistía tenía por propósito asegurar la impunidad de los responsables de graves violaciones a los derechos humanos. Desde hace casi una década la norma no es aplicada por la judicatura, lo que coincide con la condena internacional al Estado de Chile por la Corte Interamericana de Derechos Humanos, en el caso Almonacid Arellano. Véase Sentencia del caso Almonacid Arellano y otros con Chile, Corte Interamericana de Derechos Humanos, serie C 154, 26 
pudo prosperar y así satisfacer sus fines. Finalmente, la causa fue sobreseída temporalmente, lo que reafirmó la sensación de impunidad y desamparo de su familia sobreviviente.

Tras la reactivación de la causa y luego del retorno de la democracia, el Poder Judicial realizó diversos esfuerzos para proseguir con la persecución penal (Jara Bustos, 2016). Jueces con dedicación exclusiva y ministros en visita extraordinaria conocieron estos antecedentes. Veintiséis años transcurrieron desde el inicio del proceso hasta que el 6 de diciembre de 2004, el entonces juez con dedicación exclusiva del Quinto Juzgado de Letras del Crimen de Santiago, Juan Carlos Urrutia Padilla, dictó el primer auto de procesamiento en la causa ${ }^{13}$, en contra de Mario Manríquez Bravo, oficial militar a cargo del Estadio Chile, por su participación en calidad de autor del delito, consumado, de homicidio calificado de Víctor Jara.

Tras dicha resolución, el 26 de mayo de 2009, el ministro en visita Juan Eduardo Fuentes Belmar sometió a proceso a José Paredes Márquez, en la época de los hechos un soldado conscripto, por su participación punible en calidad de autor del delito consumado de homicidio calificado en la persona de Víctor. Este conscripto fue la primera persona del Ejército en relatar cómo había muerto Víctor Jara; sin embargo, al ser el último eslabón en la cadena de mando, todavía quedaba mucho por investigar ${ }^{14}$.

Debe destacarse que el mayor avance en lo que a la satisfacción de los fines del proceso criminal se refiere se produjo principalmente bajo la instrucción desarrollada por el ministro Miguel Vázquez Plaza, de la Corte de Apelaciones de Santiago, quien agotó todos los medios a su disposición para esclarecer los hechos criminales y determinar las participaciones de los sujetos que intervinieron en los mismos. Expresión de ello son los autos de procesamiento que se dictaron el 26 de diciembre de 2012 -complementado por decisión del 28 del mismo mes-, el 10 de octubre de 2013, el

de septiembre de 2006. Excepciones preliminares, fondo, reparaciones y costas. Sin embargo, la misma no ha sido anulada, como sí ocurrió en Argentina.

13. Conforme al artículo 274 del Código de Procedimiento Penal, el procesamiento es una resolución que el juez dirige contra el inculpado que ha sido interrogado judicialmente en tal calidad, ya reunidos, además, antecedentes de la causa que justifiquen la existencia del hecho punible y, asimismo, con presunciones fundadas de que el inculpado ha tenido participación criminal en él, ya sea como autor, cómplice o encubridor.

14. Auto de procesamiento de 26 de mayo de 2009, dictado por el entonces ministro en visita extraordinaria Juan Eduardo Fuentes Belmar, quien a la época del pronunciamiento de la referida resolución integraba la Corte de Apelaciones de Santiago. La investigación desplegada posteriormente por el ministro Miguel Vázquez Plaza evidenció que ésta, en la época de la dictación de la decisión señalada, no estaba agotada, por lo que era necesario desplegar todos los medios posibles para finalizar debidamente la etapa investigativa. 
29 de agosto de 2014 y el 2 de septiembre de $2014^{15}$. Entre estos sujetos procesados se encuentra uno que, en la época de los hechos, detentaba el grado de teniente en el Ejército de Chile, llamado Pedro Pablo Barrientos Núñez, quien luego del término de la dictadura se desvinculó del Ejército de Chile y abandonó nuestro país con rumbo a Estados Unidos, país en el cual se radicó y en donde reside en la actualidad. Dada tal condición, el 26 de diciembre de 2012, el ministro instructor requirió a la Corte Suprema la extradición activa de este sujeto, petición que fue acogida por el Tribunal el 30 de enero de 2013, ampliada por decisión del 31 de agosto de 2016, y formalizada al estado requerido, encontrándose ésta pendiente de resolución.

Cabe señalar, además, que el 18 de diciembre de 2013, el ministro Miguel Vázquez Plaza ordenó la acumulación del proceso sustanciado para investigar la causa Víctor Jara, a la causa rol 16.379-2005, también instruida por él, en calidad de ministro de fuero, para investigar los hechos criminales perpetrados contra Littré Quiroga Carvajal y sancionar a los responsables.

El 21 de julio de 2015, el ministro, previo cierre del sumario criminal, elevó la causa a plenario y acusó ${ }^{16}$ como autores del delito de homicidio calificado de Víctor Lidio Jara Martínez a Hugo Hernán Sánchez Marmonti, Raúl Aníbal Jofré González, Edwin Armando Roger Dimter Bianchi, Nelson Edgardo Haase Mazzei, Jorge Eduardo Smith Gumucio, Ernesto Luis Bethke Wulf, Juan Renán Jara Quintana, Hernán Carlos Chacón Soto y Patricio Manuel Vásquez Donoso; como autores del delito de secuestro simple cometido en la persona de Víctor, a Hugo Hernán Sánchez Marmonti, Edwin Armando Roger Dimter Bianchi, Nelson Edgardo Haase Mazzei, Jorge Eduardo Smith Gumucio, Ernesto Luis Bethke Wulf, Juan Renán Jara Quintana, Hernán Carlos Chacón Soto y Patricio Manuel Vásquez Donoso; como encubridor del delito de homicidio calificado, a Rolando Camilo Humberto Melo Silva; como encubridor del delito de secuestro simple, a Ramón Camilo Humberto Melo Silva; y, como autor del delito de secuestro calificado con grave daño cometido en la persona de Víctor, a Raúl Aníbal Jofré González.

Actualmente, la causa judicial sustanciada en Chile prosigue en el mencionado estado procesal de plenario, por lo que se encuentra pendiente su juzgamiento definitivo.

15. Los mismos han sido objeto de recursos en su contra y han sido confirmados después de sus respectivas revisiones por el tribunal de alzada.

16. De acuerdo con los artículos 403 y 424 del Código de Procedimiento criminal, una vez ejecutoriada la resolución que declara cerrado el sumario, si existen procesados, el juez debe dictar una resolución fundada que dé cuenta de los delitos cometidos y de la participación que a ellos les cupiera, con expresión de los medios de prueba del sumario para acreditar unos y otros. El querellante puede adherir en esta etapa, o bien formular acusación particular. 


\section{El caso en los Estados Unidos: La Torture Victims Protection Act}

Al tratarse de crímenes contra la humanidad ${ }^{17}$, hay consenso en el derecho internacional de que se trata de hechos imprescriptibles e inamnistiables (Naciones Unidas, $1946 ; 1948 ; 1968)^{18}$. Sin embargo, surgía el problema de cómo hacer efectiva la responsabilidad de Pedro Barrientos en Estados Unidos.

En mayo de 2012, el Programa de Derechos Humanos ${ }^{19}$, entonces dependiente del Ministerio del Interior y Seguridad Pública, tomó contacto con la abogada Almudena Bernabeu, directora del Centre of Justice and Accountability de Estados Unidos. Cabe señalar que la referida organización no gubernamental, con anterioridad, había promovido, entre otras, una demanda en contra de Armando Fernández Larios ${ }^{20}$, quien a la época de ser demandado también tenía residencia en el referido país, por el caso de Winston Cabello Bravo, víctima de la Caravana de la Muerte, episodio Copiapó, por los hechos ocurridos en octubre de 1973, en la referida ciudad. Este caso (Cabello con Fernández Larios) constituyó la primera sentencia dictada por un jurado en la historia de Estados Unidos por un crimen calificado como de lesa humanidad (Bernabeu, 2007: 48).

Tras conocer los antecedentes del caso de Víctor Jara, Almudena Bernabeu, en representación del Centro y en conjunto con su equipo, decidieron promover la de-

17. Esta clasificación, y en menor medida la de crímenes de guerra, ha permitido encuadrar los crímenes de la dictadura cívico-militar (Schabas, 2010: 142 y siguientes). A diferencia de la experiencia argentina, en nuestro país no se ha defendido la idea de que estaríamos ante un caso de genocidio (Feierstein, 2015: 119 y siguientes).

18. Véase también la jurisprudencia de la Corte Interamericana de Derechos Humanos. Almonacid Arellano y otros con Chile, párrafos 110 y siguientes. Esta doctrina es plenamente aceptada por la Sala Penal de la Corte Suprema.

19. El Programa Continuación Ley 19.123, conocido como «Programa de Derechos Humanos», fue creado con la finalidad de continuar con la tarea de la Corporación Nacional de Reparación y Reconciliación, por lo que debía prestar asistencia legal y social a los familiares de las víctimas. Con la promulgación de la Ley 20.405 se le reconoce la posibilidad de presentar querellas por víctimas calificadas de ejecuciones sumarias y desapariciones forzadas (artículo 10 transitorio). Actualmente depende de la recién creada Subsecretaría de Derechos Humanos del Ministerio de Justicia y Derechos Humanos (Ley 20.885 de 2016).

20. Entre otros casos, fue requerido por los Estados Unidos por el asesinato de Orlando Letelier del Solar y Ronni Moffitt en Washington D.C. Además, ha sido requerido por la justicia de Chile en múltiples procesos, entre ellos, por ejemplo, su participación en calidad de autor en el homicidio calificado de Carmelo Soria Espinosa, en el contexto de la causa rol 1-1993, instruida por el ministro Lamberto Cisternas Rocha de la Corte Suprema; por su participación como autor en el homicidio calificado de quince víctimas, en el marco de la causa rol 2.182-1998 «Caravana de la Muerte, episodio La Serena», indagada por el ministro Mario Carroza Espinosa de la Corte de Apelaciones de Santiago; y por su participación en calidad de autor en el homicidio calificado de Ronni Moffitt, en el contexto de la causa rol 910-2011, instruida por el ministro Mario Carroza Espinosa de la Corte de Apelaciones de Santiago, entre otros. 
manda ante la justicia de Estados Unidos con el apoyo pro bono de la firma Chadbourne \& Parke de Nueva York.

El estatuto legal a emplear sería la Torture Victims Protection Act, invocado también en el caso de Winston Cabello. Si bien los Estados Unidos son conocidos por su política regresiva en lo relativo a la justicia internacional, y se han restado de suscribir algunos de los principales instrumentos internacionales tanto del sistema universal, del sistema interamericano o, incluso, el Estatuto de Roma de la Corte Penal Internacional, como destaca Almudena Bernabeu, no deja de llamar la atención en su sistema jurídico la existencia de normas que consagran, aunque sea civilmente, el principio de la jurisdicción universal (Bernabeu, 2007: 40 y siguientes).

Entre ellas se cuentan la Alien Tort Statute ${ }^{21}$, y específicamente, la Torture Victims Protection Act de 1992. Se permite, con esta última norma, presentar demandas civiles en los Estados Unidos contra individuos que, actuando en una función pública, cometan torturas o ejecuciones extrajudiciales. Si bien se trata de un procedimiento entre privados, proporciona una instancia de jurisdicción universal, aunque de alcance limitado.

Múltiples fueron los objetivos planteados por el equipo conformado al instar por la promoción de esta demanda, entre los que se destacan: i) desarrollar un trabajo conjunto con la familia de Víctor Jara, de tal manera de hacerla partícipe y protagonista de todo este proceso, teniendo en consideración que este proceso civil operaría como un juicio complementario al proceso criminal sustanciado en Chile, el que tenía por objeto el esclarecimiento de los hechos y la sanción punitiva de los sujetos que intervinieron en aquéllos; ii) dar un mensaje a los criminales de lesa humanidad de que estén donde estén, en la medida en que exista una normativa que permita investigarlos y enjuiciarlos, serán perseguidos y, para ello, todas las herramientas que franquea el derecho serán empleadas para satisfacer la eficacia de los derechos a la verdad, a la justicia y a la reparación, que asisten a las víctimas; y iii) ejercer una acción que pudiese facilitar y favorecer el que Estados Unidos pusiera a disposición de nuestra justicia al requerido, para su debido juzgamiento.

El trabajo desarrollado se extendió entre 2012 y 2016. Para afirmar la competencia de la Corte Distrital del Distrito Medio de Florida, División Orlando, de Estados Unidos para conocer del caso, se argumentó que: i) la acción deducida se ejerce bajo la Torture Victim Protection Act; ii) el Alien Tort Statute es aplicable porque los hechos constitutivos de tortura cometidos en la persona de la víctima fueron ejecutados en violación de derecho de las naciones; y iii) el demandado poseía nacionalidad chilena y estadounidense, con residencia en Deltona, Florida.

21. Esta norma es original de 1789 , tras la independencia norteamericana. Su idea era proteger a embajadores y funcionarios europeos contra actos de piratería y otros que en dicha época pudieran considerarse «violaciones del derecho de las naciones». Actualmente, se considera que permite demandar por violaciones de normas internacionales universales y obligatorias (Bernabeu, 2007: 46). 
El 27 de junio de 2016, el jurado de la señalada Corte Distrital declaró que Pedro Pablo Barrientos Núñez era culpable de los cargos que habían sido formulados en su contra, por su participación en los delitos de tortura y asesinato extrajudicial de Víctor Lidio Jara Martínez, hecho ocurrido en septiembre de 1973 en Santiago de Chile. El culpable fue condenado a pagar la suma de 28 millones de dólares por concepto de indemnización de perjuicios por el daño que se causó a la familia de la víctima, constituida, como se mencionó previamente, por su cónyuge sobreviviente y por sus hijas $^{22}$. El jurado que emitió dicho veredicto de condena era un cuerpo colegiado, integrado por personas legas aunque dirigido por un juez letrado. Dicho jurado se limitó a pronunciar su decisión de culpabilidad y a definir las cuantías de los montos indemnizatorias por los crímenes establecidos. El texto definitivo de la sentencia, redactada por el juez de distrito Roy B. Dalton hijo, de 29 de junio de 2016, se limitó a establecer que el juzgamiento final era en contra de Pedro Pablo Barrientos Núñez y en favor de las demandantes ya señaladas, por lo que se ordenaba el pago de las compensaciones indemnizatorias correspondientes ${ }^{23}$.

La justificación de la intervención de la justicia de los Estados Unidos se encuentra en el concepto de justicia universal, la cual ha sido definida como la capacidad de los tribunales de cualquier Estado para iniciar enjuiciamientos por delitos cometidos fuera de su territorio y no relacionados con ese Estado por la nacionalidad del acusado o de las víctimas, ni por daños causados a sus intereses nacionales (Amnistía Internacional, 2014: 5). En doctrina se la ha definido como aquellas normas que permiten la competencia de un Estado para perseguir, juzgar y sancionar a los responsables de determinados crímenes independiente del lugar de comisión del delito, así como de cualquier vínculo de nacionalidad, activa o pasiva, u otros motivos de jurisdicción reconocidos en el derecho internacional (Shawn, 2008: 669), aunque con el alcance limitado antes señalado. Esta jurisdicción universal se erige como una excepción al principio de territorialidad de la ley. La justicia universal, así descrita, es conocida como justicia universal plena. Cualquier restricción o limitación que se imponga al ejercicio de la justicia universal, ya sea, por ejemplo, en relación con la materia de enjuiciamiento, a la víctima o al victimario - como podría serlo la nacionalidad o la ubicación de uno u otro, por ejemplo-, o bien la exigencia de un interés nacional, nos conlleva a una justicia universal limitada, condicional o morigerada. El fundamento de la justicia universal lo constituye el carácter excepcionalmente grave de los crímenes de derecho internacional, lo que justifica el deber universal de perseguir y sancionar a quienes los han cometido.

22. Sentencia del caso Jara con Barrientos, Corte Distrital del Distrito Medio de Florida, División Orlando, Estados Unidos, caso 6:13-cv-1426-Orl-37GJK, 27 de junio de 2016.

23. Para un análisis, véase Aceves (2007: 108 y siguientes). 


\section{Conclusiones}

La justicia universal para crímenes de derecho internacional, cuando es reconocida en las legislaciones internas de los Estados y es aplicada por los órganos competentes, constituye un mecanismo que permite dar verdad, justicia y reparación a las familias de las víctimas. La condena civil de Pedro Pablo Barrientos por un tribunal extranjero por los crímenes comentados perpetrados en Chile, en la persona de Víctor Jara, es una expresión de jurisdicción universal, aun cuando los Estados Unidos no la reconozcan en plenitud.

En su vertiente más conocida, la justicia universal otorga competencia a un Estado para enjuiciar a los responsables de crímenes de derecho internacional, independiente del lugar de comisión del delito, así como cualquier vínculo o motivo de jurisdicción generalmente reconocido en el derecho internacional. En este caso, al ser un procedimiento privado, constituye una manifestación limitada de la misma, sin perjuicio de constituir, igualmente, una forma de reparación y un antecedente que podría servir para la solicitud de extradición que pesa sobre Pedro Barrientos Núñez, requerido en Chile.

El caso de Víctor Jara Martínez representa uno de los múltiples crímenes de la dictadura que esperan justicia. Como su familia sabe bien, la preocupación que existe internacionalmente respecto de su caso permite abrir el debate sobre las demás víctimas de la dictadura cívico-militar chilena, en el entendido de que todos los casos son igualmente importantes y que no existen ni debe haber tratamientos privilegiados, lo que es plenamente coherente con el compromiso político y moral de Víctor Jara. En ese contexto, se debe entender que, por mucho que se empleen procedimientos civiles o criminales, lo cierto es que, más que ser un juicio entre dos partes (con intereses exclusivamente privados), éste es un asunto que compete a la sociedad en su conjunto.

De experiencias como ésta se construye un futuro en que se reconozca el derecho de vivir en paz, lo que legitima la idea de una justicia que pueda proteger a las personas de las atrocidades, sin importar su nacionalidad y ni el lugar del mundo donde se encuentren.

\section{Referencias}

ACEves, William (2007). The anatomy of torture. A Documentary History of Filartiga v. Pena Irala. Leiden: Martinus Nijhoff Publishers.

Amnistía Internacional (2014). Análisis de Amnistía Internacional sobre la reforma de la jurisdicción universal en España tras la aprobación de la LO 1/2014. Madrid: Amnistía Internacional. Disponible en http://bit.ly/ZGimtO.

Bernabeu, Almudena (2007). «La jurisdicción universal en Estados Unidos». En Sil- 
via Escobar, Carlos Castresana, Carmen Lamarca, Almudena Bernabeu, Hernán Hormazábal, Manuel Ollé, Antonio Aranibar, María Elena Rodríguez, José María Medina y Carlos Santos, Derechos humanos y desarrollo. Justicia universal en el caso latinoamericano. Barcelona: Icaria.

Comisión Nacional de Verdad y Reconciliación (1991). Informe de la Comisión Nacional de Verdad y Reconciliación. Tomos I, II y III. Santiago: La Nación.

Escalante, Jorge y otros (2013). «Víctor Jara, cuarenta años esperando justicia». En Los crímenes que estremecieron a Chile. Las memorias de La Nación para no olvidar (pp. 26 y siguientes). Santiago: Ceibo.

Feierstein, Daniel (2015). Juicios. Sobre la elaboración del genocidio II. Buenos Aires: Fondo de Cultura Económica.

Herrero, Víctor (2014). Agustín Edwards. Una biografía desclasificada del dueño de El Mercurio. Santiago: Debate.

JARA, Joan (2007). Víctor, un canto inconcluso. Santiago: Lom.

Jara Bustos, Francisco (2016). «Entrevista a Nelson Caucoto: 'Hay delitos que son perseguibles en cualquier tiempo o lugar. La imprescriptibilidad es un logro de nuestra época'». Anuario de Derechos Humanos, 12: 253-259. DOI: 10.5354/0718-2279.2016.42727.

Kornbluh, Peter (2013). Pinochet. Los archivos secretos. 2. ${ }^{\text {a }}$ ed. ampliada. Barcelona: Crítica.

NaCiones Unidas (1946). «Afirmación de los principios de derecho internacional reconocidos por el estatuto del Tribunal de Núremberg».

-. (1948). «Convención para la prevención y sanción del delito de genocidio».

-. (1968). «Convención sobre la imprescriptibilidad de los crímenes de guerra y de lesa humanidad».

Prats, Carlos (1985). Memorias. Santiago: Pehuén.

Schabas, William (2010). The International Criminal Court: A commentary on the Rome Statute. Oxford: Oxford University Press.

Schmadel, Lutz (2013). Dictionary of minor planet names. $3 .{ }^{a}$ ed. Heidelberg: Springer. SHAw, Malcolm (2008). International Law. Cambridge: Cambridge University Press.

\section{Sobre los autores}

Francisco Jara Bustos es abogado. Licenciado en Ciencias Jurídicas y Sociales, Universidad de Chile. Becario del Magíster en Derecho con mención en Derecho Internacional por la misma universidad. Profesor colaborador del curso «Migraciones contemporáneas y racismo en Chile», Universidad de Chile. Integrante del equipo jurídico de la Agrupación de Familiares de Ejecutados Políticos (AFEP). Su correo electrónico es franciscojarabustos@gmail.com.

Francisco Ugás Tapia es abogado. Licenciado en Derecho y Bachiller en Cien- 
cias Sociales y Humanidades por la Pontificia Universidad Católica de Chile. Máster en Derechos Fundamentales por la Universidad Carlos III de Madrid, España, y estudiante del Programa de postgrado en Estudios Avanzados en Derechos Humanos impartido por la misma universidad. Integrante del estudio jurídico Nelson Caucoto Pereira y Abogados Asociados. Su correo electrónico es fugas@uc.cl. 
